\title{
Characterization of Titanium Implant Anodized in Various Electrolytes
}

\author{
Hyung-Sun Kim ${ }^{\dagger}$, Won-Il Cho, Byung-Won Cho, Joon-Bong Park*, Yin-Sik Hur* \\ Eco-Nano Research Center, Korea Institute of Science \& Technology (KIST), \\ P.O.Box 131, Cheongryang, Seoul 130-650, Korea \\ *Department of Periodontology, College of Dentistry, Kyunghee University, Seoul, Korea \\ (Received August 6, 2001 : Accepted October 5, 2001)
}

\begin{abstract}
Commercial titanium rod was anodized in three types of electrolytes such as $0.06 \mathrm{~mol} / \mathrm{L} \beta$-glycerophosphate $+0.3 \mathrm{~mol} / \mathrm{L}$ calcium acetate, $0.06 \mathrm{~mol} / \mathrm{L} \beta$-glycerophosphate $+0.3 \mathrm{~mol} / \mathrm{L}$ sodium acetate and $0.06 \mathrm{~mol} / \mathrm{L} \beta$ glycerophosphate $+5 \mathrm{mmol} / \mathrm{L}$ calcium phosphate. The titanium oxide layer $\left(\mathrm{TiO}_{2}\right)$ was characterized by scanning electron microscope (SEM), X-ray diffraction (XRD) and electron spectroscopy chemical analysis (ESCA). Numerous micropores were observed on the titanium oxide layer by SEM. The diameter of micropores increased with the increase of electrolytic voltage. The titanium oxide layer was composed of anatase structure. The phosphorous element was detected at $130 \mathrm{eV}$ binding energy, but calcium was not found in the oxide layer because of lower contents. After anodizing the oxide layer was etched in the $30 \mathrm{~g} / \mathrm{L} \mathrm{NaOH}$ solution at $80^{\circ} \mathrm{C}$ for $1 \mathrm{hr}$. The surroundings of micropores were much more smoothed and rounded than before alkaline etching.
\end{abstract}

Key words : Titanium implant, Anodizing, Alkaline etching

\section{Introduction}

Titanium and its alloy have been used as implant materials because of their good biocompatibility with bone. ${ }^{1-3)}$ This biocompatible effect may be attributed to the titanium oxide layer naturally formed on the surface. Stable titanium oxide layer on the titanium surface prevents leakage of titanium ions, and results in excellent resistance to corrosion. These properties of the natural oxide layer may explain the favorable tissue response of titanium in comparison with many other metal implants. However, because titanium and other metals have no bond to bone chemically, the osseointegration only depends on mechanical interlocking between bone and titanium surface. It is accepted that success rates of machined surface implant are lower in poor quality bone, in the posterior maxilla and in some bone grafting sites. ${ }^{4)}$ Furthermore, recently more emphasis has been placed on altered protocols involving single stage surgery and immediate loading. Therefore, many trials to increase the surface areas for strong and stable mechanical interlocking have been proceeded. Even if the hydroxyapatite (HA) coatings were developed for inducing chemical bonding to bone, there have been several problems with HA coatings. HA plasma coating has low fatigue strength, degradation and delamination during long-term implantation, and weak adherence to base metallic substances. Recently it has been found that the chemical composition and surface structure of implants affected the adhesion force between implant and bone tissue ${ }^{5-6)}$.

Buser $^{7)}$ reported that the degree of bone to implant contact is related with an increasing roughness of the implant surface. Gotfredsen ${ }^{8)}$ found that $\mathrm{TiO}_{2}$ blasted implant showed better bone-to-implant contact compared with untreated titanium and its alloy. In addition, many authors stated that a strong mechanical anchorage can be achieved by a proper surface treatment. Therefore, many implant manufacturers have tried to improve implant stability and load bearing capacity in low bone quality by modifying implant surface topography. Among methods for modifying implant surface topography, anodizing is a good method to give excellent biocompatibility as forming thick and stable porous oxide structure by anodic sparking discharge at high electrolytic voltage. Spark discharges occur on titanium surface ununiformly, which generates a large amount of heat. Anodic sparking discharge process was first proposed by Kurze ${ }^{9)}$ and Ishizawa ${ }^{10)}$ described this interesting method thoroughly. They reported that a thin and porous amorphous $\mathrm{TiO}_{2}$ layer can be obtained on titanium and its alloy by anodic sparking discharge method. Also it was found that an anodic titanium oxide contained $\mathrm{Ca}$ and $\mathrm{P}$, which were accompanied by anodizing titanium in electrolyte containing calcium and phosphorous compound. This compounds enhance rapid fix as well as the adhesion force between bone and implant.

In this study, the effects of various anodizing electrolytes were examined for implant material, and porous oxide films formed by anodizing were characterized by SEM, XRD and ESCA analysis.

\section{Experimental}

Commercially pure titanium rod $(99.9 \%$, diameter: $5 \mathrm{~mm}$,

${ }^{\dagger}$ E-mail: kimhs@kist.re.kr 
length: $40 \mathrm{~mm}$ ) was anodized up to $200-330 \mathrm{~V}$ in various aqueous electrolytes at room temperature. Prior to anodizing titanium rod, it was degreased with acetone and chemically etched using a $3 \%$ hydrofluoric acid and $15 \%$ nitric acid. The anodization was carried out at constant current density $\left(50 \mathrm{~mA} / \mathrm{cm}^{2}\right)$ using a controlled DC power supply (Jisang Co.). Three types of different electrolytes such as $(0.06 \mathrm{~mol} / \mathrm{L}$ $\beta$-glycerophosphate $+0.3 \mathrm{~mol} / \mathrm{L}$ calcium acetate $),(0.06 \mathrm{~mol} / \mathrm{L}$ $\beta$-glycerophosphate $+0.3 \mathrm{~mol} / \mathrm{L}$ sodium acetate $)$ and $(0.06$ $\mathrm{mol} / \mathrm{L} \beta$-glycerophosphate $+5 \mathrm{mmol} / \mathrm{L}$ calcium phosphate) were prepared to form titanium oxide layer. Nickel electrode was used as a counter electrode. After anodizing these samples were washed with distilled water and dried at $50^{\circ} \mathrm{C}$ for $10 \mathrm{~min}$ in oven. Some samples were etched in $30 \mathrm{~g} / \mathrm{L} \mathrm{NaOH}$ solution at $80^{\circ} \mathrm{C}$ for $1 \mathrm{hr}$ after anodizing.

The microstructure of anodized sample was observed by scanning electron microscope (SEM; Hitachi, S-4200). The crystal structure and surface analysis profile of the specimen were analyzed by X-ray diffractometer (XRD; Rigaku, RINT/DMAS 2500) and (ESCA; PHI 5800) respectively.

\section{Results}

\subsection{Morphology of titanium oxide layer}

Fig. 1 shows the microstructure of the porous titanium oxide formed in the electrolytic solution containing $\beta$-glycerophosphate + sodium acetate at $200,250,300$ and $330 \mathrm{~V}$. The diameter of the micropores tends to increase with the increase of electrolytic voltage. Anodic sparking reaction occurs at $c a .200 \mathrm{~V}$. The reaction became more vigorous with higher voltage and the temperature of the electrolyte was reached to 80 . At $200 \mathrm{~V}$ the micropores were less than $1 \mu \mathrm{m}$ in diameter and the color of the titanium oxide layer was grayish-white. At $300 \mathrm{~V}$ this diameter was $2 \sim 3 \mu \mathrm{m}$, but the surface of oxide film was rough and the distribution of pore was not uniform in comparison with the surface structure of the oxide film formed at $250 \mathrm{~V}$. This phenomenon was much more severe at $330 \mathrm{~V}$. Ishizawa ${ }^{5)}$ reported that the microstructure of oxide film became irregular and many cracks were observed with increasing electrolyte concentration as well as the electrolytic voltage. But these cracks were not found in our experiment because of the different electrolytic solution.

Fig. 2 shows the microstructure of the porous titanium oxide formed in the electrolytic solution containing $\beta$-glycerophosphate + calcium acetate at $250 \mathrm{~V}$. It can be expected that calcium element exists in the oxide layer. The incorporation of calcium and phosphorous into the oxide layer promotes the bonding strength between the layer and bone tissue. As shown in Fig. 2(a) the structure of oxide films was similar to that in the former electrolyte, but after alkali etching this pat-

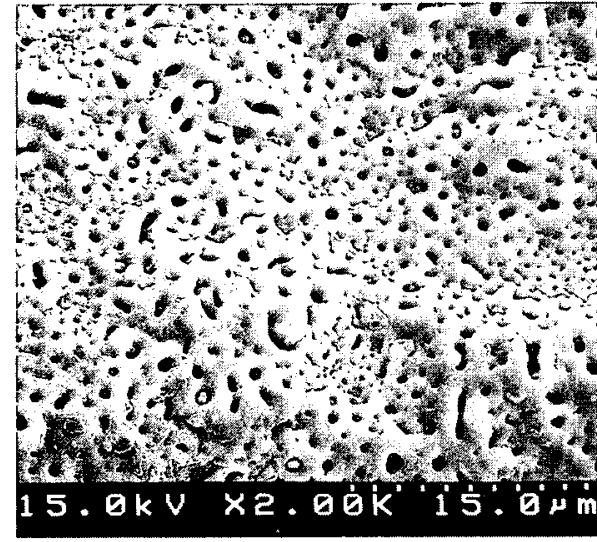

(a)

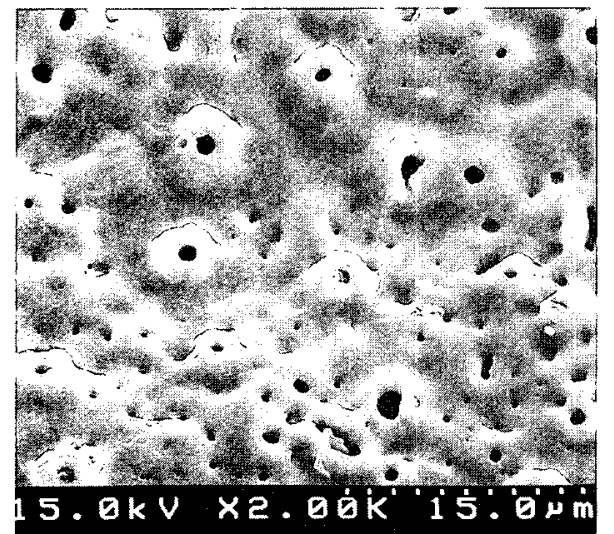

(c)

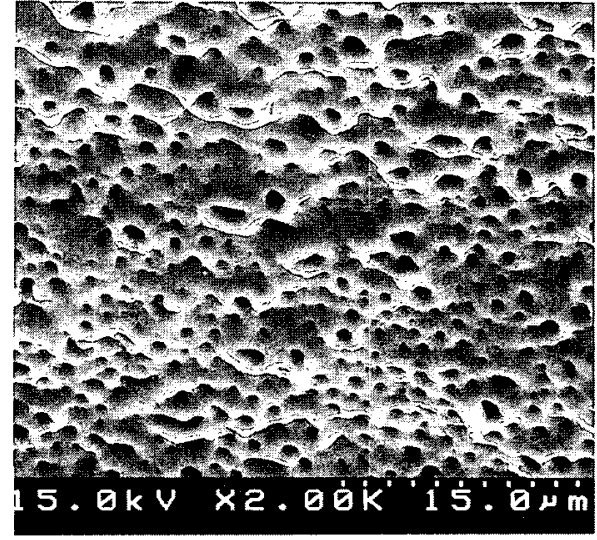

(b)

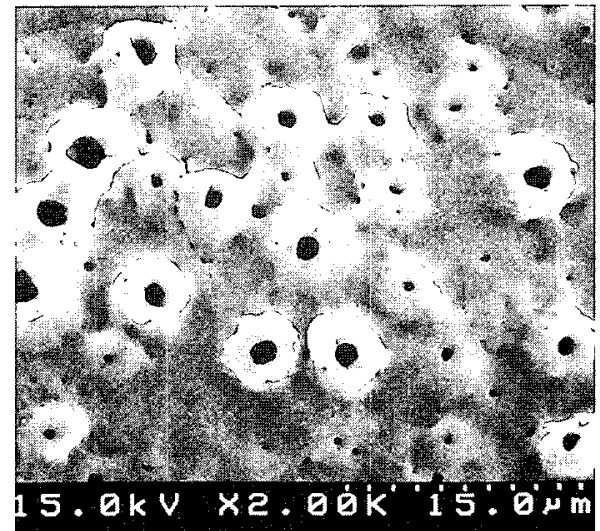

(d)

Fig. 1. Scanning electron micrographs of the titanium oxide layer formed in $0.06 \mathrm{~mol} / \mathrm{L}$-glycerophosphate $+0.3 \mathrm{~mol} / \mathrm{L}$ sodium acetate electrolyte at $50 \mathrm{~mA} / \mathrm{cm}^{2}$ (a: $200 \mathrm{~V}$, b: $250 \mathrm{~V}$, c: $300 \mathrm{~V}$, d: $330 \mathrm{~V}$ ). 


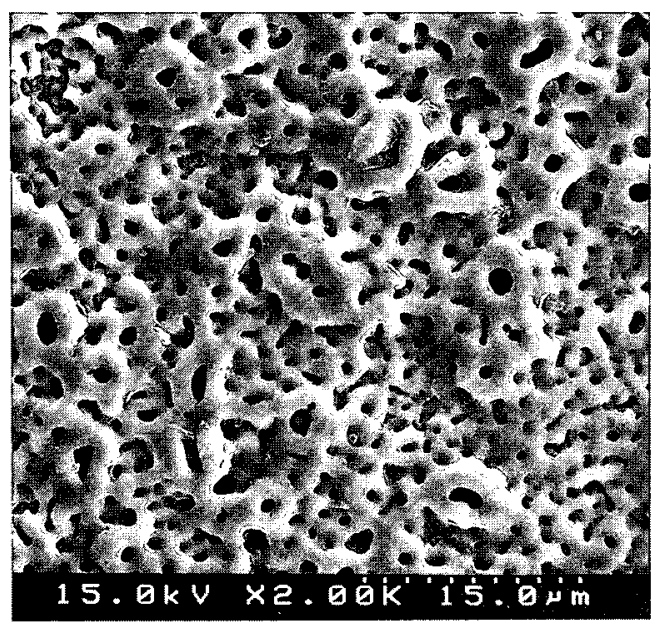

(a)

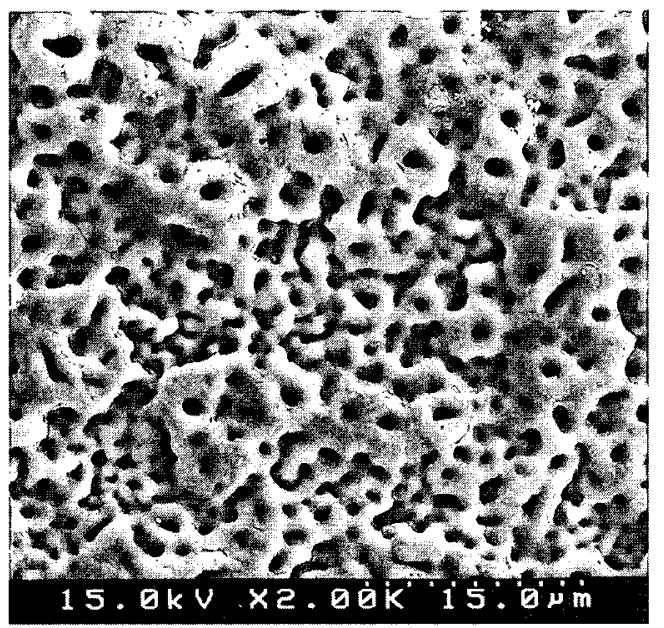

(b)

Fig. 2. Scanning electron micrographs of the titanium oxide layer formed in $0.06 \mathrm{~mol} / \mathrm{L}$-glycerophosphate $+0.3 \mathrm{~mol} / \mathrm{L}$ calcium acetate electrolyte at $250 \mathrm{~V}$ (a: before alkaline etching, b: after alkaline etching).

tern was changed significantly as shown in Fig. 2(b). The surroundings of the micropores were smoothed and the size of pore diameter increased.

Fig. 3 shows the structure of oxide film formed in the electrolytic solution containing $0.06 \mathrm{~mol} / \mathrm{L} \beta$-glycerophosphate $+5 \mathrm{mmol} / \mathrm{L}$ calcium phosphate acetate at $350 \mathrm{~V}$. In this electrolyte the electrolytic voltage increased rapidly because of the lower conductivity of electrolyte. Calcium phosphate is insoluble in water and this effect may contribute to low ionic conductivity. The size of pore diameter was much smaller than that of pore diameter formed in other electrolytes. The pore structure was not found in this electrolyte at lower voltage than $350 \mathrm{~V}$.

\subsection{XRD patterns of titanium oxide layer}

Fig. 4 shows $\mathrm{X}$-ray diffraction patterns of the surface film before and after anodizing in the electrolytic solution containing $\beta$-glycerophosphate + sodium acetate at $250 \mathrm{~V}$. The oxide film mainly consisted of anatase tetragonal structure.

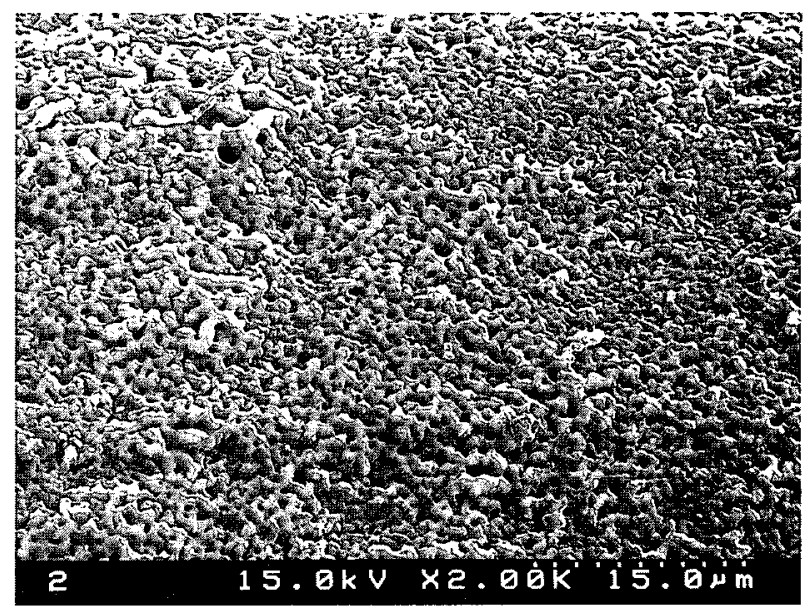

Fig. 3. Scanning electron micrographs of the titanium oxide layer formed in $0.06 \mathrm{~mol} / \mathrm{L}$-glycerophosphate $+5 \mathrm{mmol} / \mathrm{l}$ calcium phosphate electrolyte at $350 \mathrm{~V}$.

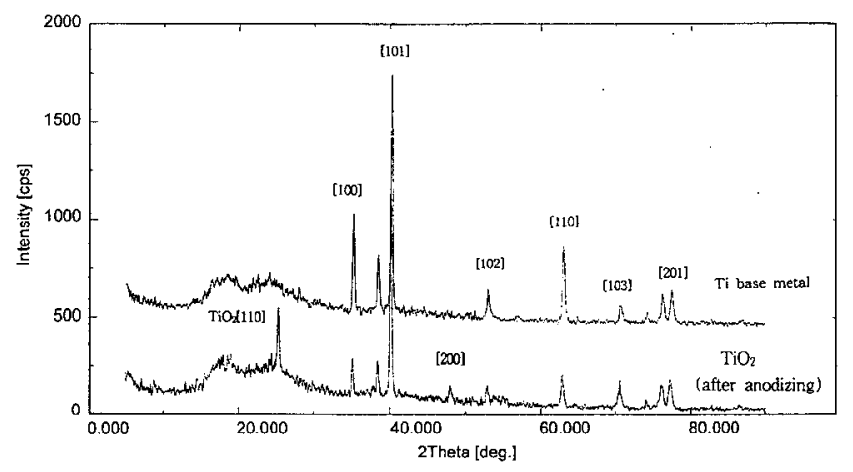

Fig. 4. X-ray patterns of titanium surface before and after anodizing in $0.06 \mathrm{~mol} / \mathrm{L}$-glycerophosphate $+0.3 \mathrm{~mol} / \mathrm{L}$ sodium acetate electrolyte at $250 \mathrm{~V}$.

In general, amorphous phase is penetrated easily by bacteria because of low density. Therefore, this structure is not suitable for implant material. In our experiment, it is expected that the function of implant can be improved without additional heat treatment because of crystal structure. Ogino reported ${ }^{10)}$ that the oxide layer formed after hydrothermal treatment consisted of anatase and only a little rutile. In addition, HA layer is formed on the titanium oxide layer after hydrothermal treatment. This layer is a single crystal or have very high crystallinity. But this hydrothermal treatment is usually conducted at high temperature and pressure condition. Despite its high crystallinity such a porous titanium oxide layer seems to be helpful to the formation of HA layer by other dry coating method in the absence of severe condition.

\subsection{ESCA analysis of titanium oxide layer}

Fig. 5 shows ESCA analysis results of titanium oxide layer formed in the electrolytic solution containing $\beta$-glycerophosphate + calcium acetate at $250 \mathrm{~V}$. Phosphorous element was detected at $130 \mathrm{eV}$ binding energy. Therefore, $\beta$-glycerophosphate is a suitable phosphorous compound to form the titanium 


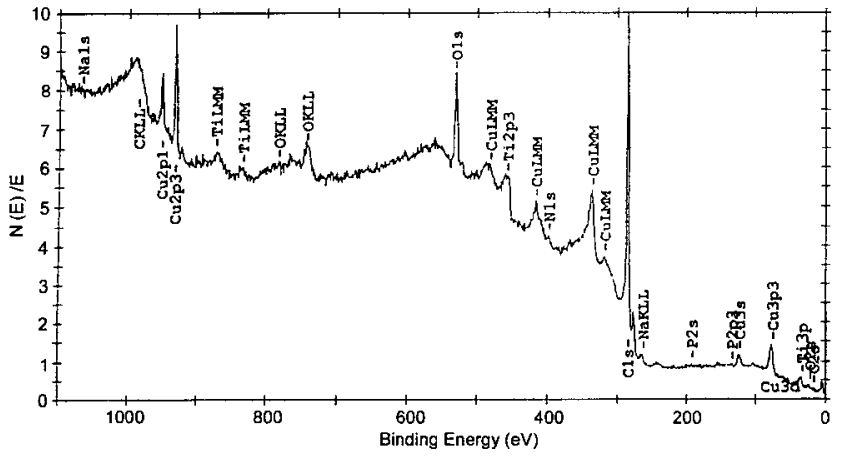

Fig. 5. ESCA profiles of titanium oxide layer formed in $0.06 \mathrm{~mol} / \mathrm{L}$ glycerophosphate $+0.3 \mathrm{~mol} / \mathrm{L}$ calcium acetate electrolyte at $250 \mathrm{~V}$.

oxide layer containing phosphorous element. But calcium element was not found in the titanium oxide layer. It may ionically exist in the $\mathrm{TiO}_{2}$ matrix or the contents of calcium are low because calcium acetate is not easily dissolved in an aqueous solution of $\beta$-glycerophosphate. Ishizawa reported ${ }^{5)}$ that calcium was incorporated more than phosphorous over $250 \mathrm{~V}$, and the incorporation of calcium continued up to $400 \mathrm{~V}$. When the electrolytic voltage was high, the microstructure of oxide layer surface became irregular (Fig. 1c) and might not be stable. Therefore it is considered that calcium and phosphorous are not uniformly distributed in the oxide layer formed at high electrolytic voltage.

\section{Discussion}

Titanium is a reactive metal with a native oxide layer thickness of about $4 \mathrm{~nm}$. Corrosion resistance of titanium is induced by such a insoluble surface oxide, and the titanium oxide layer is readily regenerated even if destroyed. Because the surface oxide of an implant comes into direct contact with the surroundings of proteins, cells and tissues, it is widely assumed that the biocompatibility of titanium is closely associated with the properties of its surface oxide layer. Several studies in vitro and vivo have shown the properties of a modified surface oxide layer and its influence on the biological response. Anodizing can improve early bone response to implants surface. Hazan et al. ${ }^{13)}$ suggested that a modified surface oxide layer may be a preferable substrate for differentiation and growth of bone-producing cells. Rough porous structure is formed by sparking on smooth machined titanium when the certain conditions such as electrolyte composition, anodic potential, current, temperature, and electrode geometry are met. Byeon ${ }^{14)}$ reported that the sparking during anodizing is accompanied by the local deposition and dissolution of the oxide film through discharging, and the crystallinity of the anodic oxide film increases with the increase of the anodizing voltage, but it decreases with the increase of the electrolyte concentration. Anodized tita- nium surface without rough topography by sparking didn't show improved early bone response to implant surface. This result suggests that the improved bone response can be made by rough porous surface caused by anodizing rather than thick oxide layer itself. In the comparative study of machined and anodized surfaces, it was clearly demonstrated that the anodized surfaces showed greater removal torque implying a more stable anchorage. A study on dogs has demonstrated significantly higher removal torque values when anodized surface implants are used in comparison with the doubleacid-etched surface treatment and similar tissue reactions ${ }^{15}$.

\section{Conclusions}

Titanium oxide layer $\left(\mathrm{TiO}_{2}\right)$ was formed by anodizing titanium in various aqueous electrolytes containing calcium and phosphorous compound. The surface of this layer became rough and porous with the occurrence of anodic sparking discharge. The diameter of micropores increased with the increase of electrolytic voltage, but the distribution of micropores was not uniform at higher voltage. This layer consisted of anatase structure. Phosphorous element existed in the oxide layer and calcium element was not detected. After alkaline etching the surroundings of micropores were more smoothed and rounded.

\section{References}

1. J. A. Filbey and J. P. Wightman, J. Adhesion, 28, 1(1989).

2. H. Ishizawa and M. Ogino, J. Materials Science, 34, 5893(1999).

3. A.C. Kennedy, R. Kohler and P. Poole, Int. J. Adhesion and Adhesives, 3, 133(1983).

4. P. J. Henry, J. Prosthet. Dent. 79, 100(1998).

5. H. Ishizawa and M. Ogino, J. Biomedical Materials Research, 29, 65(1995).

6. G. A. EL-Mahdy and S. S. Mahmoud, J. Materials Science Technology, 14, 241(1998).

7. D. Buser, R. K. Schnek, S. Steinemann, J. P. Fiorellini, C. H. Fox and H. Stich, J. Biomed. Mater. Res., 25, 889(1991).

8. K. Gotfredsen, A. Wennerberg, C. Johanson and LT. Skovgaard, $J$. Biomed. Mater. Res., 29, 1223(1991).

9. P. Kurze, W. Krysmamm and HG. Schneider, Cryst. Res. Technol, 21, 1603(1986).

10. H. Ishizawa, M. Fujino and M. Ogino, J. Biomedical Materials Research, 35, 199(1997).

11. A. Wennerberg, T. Albreaksson and B. Anderson, Int. J. Oral Maxillofac Implants, 11, 38(1996).

12. C. Larsson, P. Thomsen and BO. Aronsson, Biomaterials, 17, 605(1996).

13. R. Hazan, R. Brener and U. Oron, Biomaterials, 14, 570(1993).

14. K. J. Byeon, C. S. Kim, X. Zhu and K. H. Kim, J. Biomed. Eng. Res., 21, 273(2000).

15. J. Gottlow, P. J. Henry, A. E. S. Tan, B. P. Allan, C. Johnson and J. Hall, Applied Osseaintegration Research, 1, 28(2000). 